\title{
Pedagogical Support of the Self-Development of Adolescents in Additional Education in the Framework of the Reflective-Value Approach
}

\author{
Irina V. Ivanova \\ Department of social adaptation and organization of work with youth, Tsiolkovskiy Kaluga State University, Kaluga, \\ Russia \\ Corresponding author.Email: ivanovadiv@yandex.ru
}

\begin{abstract}
The article is devoted to the problem of pedagogical support of the self-development of adolescents in additional education, implemented within the framework of the methodology of the reflective-value approach developed by the author in the framework of the scientific school of existential pedagogy under the guidance of Professor M.I. Rozhkov. In the context of the reflexive-value approach, the pedagogical support of the self-development of adolescents sets as their first priority the task of forming value meanings in the adolescent, and, on the basis of this, constructs and implements the project of his life. The most effective implementation of this approach can be represented in the system of supplementary education for children, which involves the organization by pupils of the space of their life based on choice, and contributing to the formation of a teenager's readiness for self-development.
\end{abstract}

Keywords: self-development, project of one's own life, pedagogical support, adolescence, existentialism, reflective-value approach

\section{INTRODUCTION}

The relevance of the research topic is due to modern processes of development of world and domestic education, focused on the formation of a free, selfdeveloping personality. A characteristic feature of the current stage of development of the education system is the orientation towards the maximum individualization of the child's education. This trend is presented in the content of the new Federal state educational standards, in the social project for the development of the individual, society and the state "Our New School", the National Doctrine of Education in the Russian Federation, in the "Concept for the Development of Further Education of Children of the Russian Federation" (2014). The materials of the normative educational document "Strategies for the development of upbringing in the Russian Federation for the period until 2025" mention that today important attention should be paid to the upbringing in children of the ability to make the right choice, the formation of positive life guidelines and plans. The education of a free personality, ready to bear responsibility for their actions, thoughts and actions is an important task of modern education. This target provides for the implementation of the subjective position of the child and the construction of a cooperative relationship between the teacher and the children. It is through the development of this position in the child in the process of social contact with adults that he becomes aware of himself as a free person.

This direction of education development is correlated with the educational policy trend of different countries of the world, as evidenced by the scientific works of foreign scientists in the field of pedagogy and psychology: M. Cai [1]; A. Carr [2]; G. Edwards, A. Turner [3]; A. Khafizova, V. Zakirova [4]; I. Maksymchuk, O. Sahach, I. Demchenko, S. Furdui, B. Maksymchuk, O. Protas, E. Kyzko [5]; T. Ng [6]; I. Yarmakeev, A. Kaplan, N. Valiakhmetova, R. Akhmadullina, A. Sharafieva [7]; Y. Zhan, Z. H. Wan [8]. The implementation of the approach is possible through the development of individual trajectories (routes) of self-development of students, individual educational programs in the context of specially organized pedagogical support for selfdevelopment of children and adolescents.

Based on the scientific works of scientists in the field of developmental psychology: L.S. Vygotsky [9], V.V. Davydov [10], M. Cle [11], A.N. Leontiev [12], J. Piaget [13], G.S. Sullivan [14], V.I. Slobodchikov [15], D.I. Feldstein [16], S. Hall [17], G.A. Zuckerman [18], D. Elkind [19], D. B. Elkonin [20], E. Erickson [21], we conclude that a special role in the formation of a selfdeveloping personality should be given to adolescence, the main neoplasms of which are a sense of adulthood, the formation of subjectivity, critical thinking, the 
development of volitional qualities and reflection, the formation of value orientations, which creates psychological prerequisites for the formation of a teenager's readiness for independent and responsible choice. The tasks of adolescence are associated with the setting of life goals, with the design of their present and future capabilities.

However, in modern sociocultural conditions, a teenager is not always ready for an existential choice, which is predetermined by the current state of his life. Today, the self-determination space of most adolescents has been narrowed; the load associated with life planning is carried out by mythologems broadcast by the immediate environment of adults and the media; often the content of basic general education does not become for teenagers material for self-development. Extra-curricular systems television, the Internet - are beginning to fulfill an increasingly active educational function, which creates a whole system of challenges for educating a teenager, since it not only directly integrates a person into the broadcast space (for example, the Internet) with its frequency communication capabilities, but also actively forms the choice and preferences for the teenager. There is a risk of personality deformation, the choice of socially disapproved behaviors, and a decrease in the social activity of adolescents.

\section{PROBLEM STATEMENT}

In the circumstances, it is especially important to form a teenager's inner perception of the dependence of the goals on his own choice of a path in life, an understanding of the possibility of creating his own project of existence, a conscious choice of life goals, the manifestation of conscious activity in solving problems of overcoming difficulties.

It is necessary to seriously consider the possibility of launching the processes of self-development of adolescents by means of educational practice. Based on the works of domestic scientists: V. A. Berezina [22], A.K. Brudnov [23], G.P. Golovanov [24], V.A. Gorsky, A.Y., Zhurkina [25], E.E. Chepurnykh [26], we believe that the solution to the problem of educating a teenager who is ready for self-development has the possibility of natural implementation in the conditions of additional education as an educational system with broad educational opportunities and unique to the Russian education system. The educational environment of continuing education involves the formation by pupils of their own space of life based on choice. In the additional education of children as a flexible and variable system, based on the lack of standards and providing the child with the opportunity to choose the profile of activity, creative association, teacher, occupation regime, a significant resource is laid for the self-development of a teenager through the process of organizing his own life. At the same time, today in the mass practice of continuing education of children, effective models of pedagogical support for the selfdevelopment of adolescents are not being introduced, the technological training of teachers of educational organizations in the implementation of this type of pedagogical activity is insufficient.

On the one hand, an important trend in the development of modern education is the creation of conditions for the selfdevelopment of adolescents, focuses on the use of educational opportunities for additional education of children, there are theoretical, methodological and methodological developments in the field of existential pedagogy that meets the tasks of self-development of adolescents. On the other hand, the analysis of the studied problem shows that the completeness of scientific knowledge in the field of pedagogical foundations for supporting the self-development of adolescents, ensuring their readiness for building and implementing projects of their own lives in the system of additional education, has not been achieved; there is no pedagogical concept explaining the essence and features of pedagogical activity aimed at forming the readiness of pupils to independently design their lives on the basis of reflection and prioritization of existing values and value orientations.

The need to resolve this contradiction led to the formulation of the problem, which consists in determining the theoretical and methodological foundations and the search for methodological tools (technologies, methods, forms, techniques) aimed at stimulating adolescents' awareness of the meaning of their own life, its value components and the implementation of their own life projects on their basis.

\section{RESEARCH QUESTIONS}

As part of our study, it is important to answer the questions:

1. What is the basis for self-development of a teenager?

2. What methodological approach in pedagogy considers self-development as the creation by a pupil of a project of his own life?

3. What methodological approach to pedagogical science can become the basis for the implementation of pedagogical support for the self-development of adolescents in educational practice aimed at creating the conditions for adolescents to develop their own life projects?

\section{PURPOSE OF THE STUDY}

The goal is to develop and theoretically substantiate a methodological approach and methodological tools for pedagogical support of the self-development of adolescents in additional education, which helps teenagers to adopt life-oriented orientations that do not contradict universal 
human norms and values of life, and develop their own life projects on their basis.

\section{RESEARCH METHODS}

Methods of research is an interdisciplinary analysis of the problem and subject of research, comparative analysis, concretization, generalization, systematization, modeling.

\section{FINDINGS}

Having studied the psychological and pedagogical literature, we come to the conclusion that the motivation for self-development arises when a teenager needs to solve a problem that is significant for him, gain new knowledge, develop the qualities that will help him solve the problem (M.I. Rozhkov [27], T. N. Sapozhnikova [28], E. Fromm [29], D. McClelland [30]). Motivation for self-development occurs when a teenager clearly defines what he wants in life and what needs to be done.

The pedagogical tool that creates the conditions for the formation of the motivation for self-development is problem situations, since they give rise to the pupil's desire to find (discover or learn) the knowledge and methods of activity that are objectively necessary and sufficient to solve the problem (L.G. Peterson [31]). In the process of overcoming, the desire for self-development arises, based on the motivation for self-improvement; awareness of such an aspiration occurs through overcoming psychological barriers.

Since the process of self-development is not of a natural evolutionary, but of a practical nature, the activity in which the teenager is involved helps to identify the need for self-development, this emphasizes the importance of using the project method, professional trials and other practice-oriented methods in which the teenager encounters problem situations (P.M. Jacobson [32], S.L. Rubinstein [33], L.S. Vygotsky [9], A.N. Leontiev [12]). The motivation for self-development is formed in a social environment saturated with significant events and characterized by a special type of interaction between children and adults, which has the nature of cooperation and provides the opportunity to express a subjective position for each teenager, to reflect on the events (N.A. Chueva [34], M.I. Rozhkov, T. N. Sapozhnikova [28]). To form the teenager's motivation for self-development, it is important to understand that any interaction between him and the teacher should be an event, be carried out taking into account the series of events available to the pupil, and be personalized (M.I. Rozhkov [27], O.S. Grebenyuk, T.B. Grebenyuk [35]).

Scientists determine the basis of self-development as a search and choice of their own life's purpose, their future, "the meaning of life" (according to V. Frankl [36]), "life strategies" (according to K.A. Abulkhanova-Slavskaya [37]), which predetermines the creation of a project of their ways for self-realization, because a person, according to J.-P. Sartre [38] is a subjective project.

The existential choice made by a teenager is determined by: life-meaning orientations (according to V. Frankl [36], A.N. Leontiev [12], D.A. Leontiev [39]), life principles (according to V.S. Mukhina [40]), worldview positions (according to V.A. Petrovsky [41]), value orientations (according to L.S. Vygotsky [9]), worldview (according to D.A. Leontiev [39]), value orientations ... All the proposed phenomena are almost identical and describe in fact, a value priority chosen by a person that reflects his subjective position and predetermines the assessment of significance ty of this or that phenomenon, events in his life.

The design by the teenager of the image of the ideal "I" and the image of the ideal future takes place in reliance on the meaning-life orientations formed in a given period of time.

Research psychologists T.N. Sakharova [42], Z.V. Golysheva [43], N.A. Chueva [34] showed that adolescents are characterized by an orientation toward group interests, a wide variability of the formulated meaning of life, its weak hierarchization and differentiation of situational goals, infantilism of adolescents, their hope of supporting parents and friends, a pronounced sense of adulthood makes adolescents perform as many actions as possible and actions for its demonstration, orientation toward the goal, focused on obtaining satisfaction and interest from significant events in the present, "here and now", the teenager's future orientation is less significant. These socio-psychological characteristics of the adolescent determine the need for special pedagogical support for self-development.

The pedagogical support of self-development should contribute to the formation of the readiness of adolescents to independently design their lives on the basis of reflection and prioritization of existing values and value orientations. It should be directed, on the one hand, to creating the conditions for the formation of meaningful life orientations by saturating the life of adolescents with existential reflections during the solution of real or specially created dilemma situations by the teacher, and, on the other hand, to forming the readiness of adolescents to build self-development projects.

This pedagogical idea can be implemented in the conditions of existential concepts in pedagogy, which considers self-development as a child's implementation of his own project to improve the qualities he needs (M.I. Rozhkov [27]). This theory is methodologically based on the views of the representatives of the existential approach in philosophy (J.P. Sartre [38], V.E. Frankl [36], etc.) and in psychology (V.E. Frankl [36], K.A. AbulkhanovaSlavskaya [37], D.A. Leontiev [39] and others), who proclaimed the idea of acquiring the essence of man as a result of his own free and responsible choice.

In the framework of existential approaches in pedagogy, by the pedagogical accompaniment of self-development of students we understand the complex of actions of teachers 
as subjects of social education, ensuring the internalization of social values, the inclusion of children in significant events that contribute to the formation of the subject's life position and self-realization in accordance with it [44, p. 52]. In the course of organized support, the socially approved ideas of success are internalized and the person's active position in determining their own life guidelines is realized; there is a transition from spontaneity (under the influence of the external conditions of society to the individual) to the conscious orientation of the personality towards the formation of personality qualities necessary to achieve life goals.

As part of the implementation of the conceptual ideas of existential pedagogy, we are developing a reflective-value approach to the pedagogical support of the selfdevelopment of adolescents, which puts as a priority the task of forming value meanings in a child, and, on the basis of this, building and implementing a project of his life.

The patterns of pedagogical support, implemented in the framework of the reflective-value approach, are:

- humanistic interaction between teacher and adolescents,

- the events of the life of adolescents,

- the presence of a field of self-realization.

The organization of pedagogical support for the selfdevelopment of adolescents in the framework of reflective value is based on pedagogical principles:

- the principle of updating reflection,

- the principle of a value attitude to one's life;

- the principle of freedom of self-development and independence,

- the principle of the accumulation of experience of moral values.

It is advisable to distinguish three components of pedagogical support for determining the child's life strategy: propaedeutic, relevant, reflective.

The propaedeutic component involves the formation in the adolescent of the need for reflection of the events of his life and the understanding that overcoming the difficulties encountered in life is only possible on the basis of selfimprovement. It is at this stage that it is necessary to encourage the pupil to ask himself questions not only "Who should I be?", But also "What should I do?". At this stage of pedagogical support, it is necessary to prepare the teenager for a moral examination of what is happening, providing him with the necessary moral knowledge. The willingness of a child to create a project of his life for the near and far future is determined by a combination of value orientations, which include benevolence, tolerance towards other people, honesty, justice, selflessness, responsiveness, politeness, etc .; the ability to analyze and predict their activities, the ability to reflection, as well as knowledge of moral standards.

The actual component implies the specific activities of teachers in the period in which pupils experience a real situation of overcoming, which requires the help of teachers in determining the child's self-development tasks. Teachers discover and actualize with the child the subject of pedagogical support, which are the moral problem, difficulty, resentment of the child. Its essence, causes of occurrence are revealed, contradictions are revealed, the problem is formulated. The search for solutions to the problem is carried out and its role in solving it is determined together with the child. Adults and children analyze what is happening, predict the possibility of new difficulties and ways to overcome them. The reflective component (aftereffect component) is aimed at understanding what is happening, designing certain actions in the future, and self-correcting the existing value orientations. At this stage, the reflexivevalue attitude to a life event is simulated, an existential decision is made, and, if necessary, an adjustment is made to the project of his life created by the teenager.

An important component of the pedagogical accompaniment of the self-development of adolescents is the escort of pupils in a situation of overcoming the difficulties that the adolescent encounters when confronted with a choice, which are characteristic of "leaving the comfort zone". They give rise to experiences that can lead to the following development paths: in favor of "becoming" - self-development, personal growth, or "regression, involution" - stop in personality development. This is confirmed by studies by H. Sek, the results of which indicate that critical events can both contribute to personal growth and can be considered as a risk factor that poses a threat to physical and mental health [45].

The process of pedagogical support for the selfdevelopment of adolescents in a situation of overcoming difficulties includes several stages.

1. Stage of the "initial assessment" of the situation: the teacher, together with the teenager, discovers and actualizes the difficulties that have predetermined the "way out of the comfort zone", their causes are determined, contradictions are detected, the problem is formulated.

2. The stage of personal assessment of one's own capabilities: a search is made for solutions to the problem, the degree of adult participation in this process is determined, and the means of pedagogical support are discussed.

3. The stage of understanding, constructing new behavioral programs. A teenager (with the participation of an adult, if necessary) defines actions aimed at solving the problem.

4. The stage of implementing new behavioral programs, testing new alternatives to behavior. The teenager performs real or virtual (in the case of a simulated situation) actions aimed at solving the problem.

5. The stage of reflection of new behavioral programs. The teacher encourages the teenager to reflectively interpret the life situation on the basis of his own values, taking into account the moral principles of the sociocultural environment, to make an independent and responsible decision, to predict the future life trajectory based on it [44, p. 53]. 
The main form of pedagogical support for the selfdevelopment of adolescents in a situation of overcoming difficulties is counseling, which involves updating the solution to a real dilemma situation. The work on the analysis of dilemma situations involves the inclusion of a teenager in a dialogue, during which he independently recognizes and verbalizes the problem, the intrapersonal contradictions associated with it, searches for the causes of difficulties, analyzes the available resources, determines their need and sufficiency for solving the problem, outlines ways and means solving prognostic tasks. In the process of analyzing real dilemma situations of different types, reflection is actively involved.

In the context of organizing pedagogical support of a teenager in a situation of overcoming difficulties as a means of providing an opportunity for a conscious look at the problem and understanding the nature of the difficulties encountered that impede its solution, as well as facilitating the adoption of an informed responsible decision by the teenager, we determine the coach techniques that can be successfully applied by the teacher in the process of counseling a teenager. In addition to the coach-technician ("Setting open questions" / "Technique of strong questions", "Scale of progress towards the goal from 1 to 10", "Scale of satisfaction with progress towards the goal from 1 to 10", "Plus list" (self-assessment), " Journey to the Future ", The Wheel of Life Balance ", etc.), counseling as a form of pedagogical support for the self-development of adolescents in situations of overcoming difficulties involves the use of the following methods and techniques: situation analysis, internal negotiations, homework, information, specific wishes, metaphors (method of analogies), assisting in the search for identity, paradoxical instruction, reassessment, increasing energy and strength, positive attitude, conducting logical justification, self-disclosure, transformation of personal history, persuasion, establishing logical relationships, emotional infection.

These methods and techniques of pedagogical support for the self-development of adolescents in a situation of overcoming difficulties formed the basis for the development of self-development projects that we identified in their correlation with the types of problem situations that predetermined "leaving the comfort zone".

The pedagogical support of self-development of adolescents will be effective if the following conditions are implemented:

- the events of the educational process,

- empathic interaction,

- partnerships between mentors and followers,

- the conventionality of pedagogical support,

- an optimistic strategy of pedagogical support,

- the formation of a motivational perspective,

- social hardening of children,

- individuality in working with children,

- the willingness of teachers to implement pedagogical support for the self-development of adolescents,

- the orientation of the pedagogical support of children's self-development to the realization of the value of selfdevelopment and an active life position.

The pedagogical support of the self-development of adolescents in additional education, based on a reflectivevalue approach, is able to positively influence the processes of conscious construction by pupils of their own life projects if:

- acts as a special type of pedagogical interaction aimed at stimulating the awareness of pupils of the meaning of their own life and its value components and building on their basis a project of their own life;

- represents a special pedagogical system that has a targeted, substantive, operational-activity and analyticproductive components;

- focuses on the leading goal - to help manifest in a person's needs and ability to be a subject, ready to determine his life mission, create and implement his own life project;

- it is built taking into account a number of pedagogical laws (humanistic interaction between teacher and adolescents, the occurrence of adolescent life activity, the presence of a field of self-realization), is based on pedagogical principles (actualization of reflection, value attitude to one's life activity);

- involves the implementation of the educational process based on the ideas laid down in the model of pedagogical support for the self-development of adolescents in additional education, and aimed at creating conditions for the formation of meaningful life orientations among adolescents and building on their basis projects of their own lives;

- implements in the conditions of additional education the technology of pedagogical support for the selfdevelopment of adolescents (including in situations of overcoming difficulties) and the corresponding set of pedagogical tools (dilemma situations, coach techniques, art equipment, etc.) and forms (counseling, individual conversations);

- implements socially-orientating, developing, training, diagnostic, stimulating, organizational-activity, facilitating and reflective-evaluative functions;

- involves the organization of training of educators for the type of activity under consideration, the integration of educational resources of the educational organization of additional education of children and the sociocultural environment, pedagogical support for the selfdevelopment of adolescents and the educational process. The main expected result of pedagogical support is the personality of the adolescent, who has the willingness and ability to build and implement his own self-development project.

\section{CONCLUSION}

The basis of self-development as the creation by a teenager of a project of his own life is made up of his lifeoriented orientations that predetermine existential choice 
as a choice of the meaning of life. Proceeding from this, the pedagogical support of the self-development of adolescents should be considered as a special type of pedagogical interaction aimed at stimulating the pupils to realize the meaning of their own life and its value components and to implement the implementation of their own life project on their basis.

1. The pedagogical support of self-development contributes to the formation of the readiness of adolescents to independently design their lives on the basis of reflection and prioritization of existing values and value orientations. It is aimed, on the one hand, to create the conditions for the formation of meaningful life orientations by saturating the life of adolescents with existential reflections in the course of solving real or specially created dilemma situations by the teacher, and on the other hand, to create the readiness of adolescents to build self-development projects.

2. Based on the reflective-value approach, the pedagogical support of the self-development of adolescents creates the conditions for:

- the implementation by adolescents of a moral examination of the existing social experience, events (both real and specially created),

- awareness of the importance of environmental friendliness of choice,

- adoption by the subject of self-development of optimal decisions in various situations of choice (social, professional, existential);

- the formation of a teenager's perception of a situation of overcoming difficulties as an opportunity for selfdevelopment,

- construction by pupils of their own life projects, reflecting their subjective position.

4. The most effective implementation of this approach can be represented in the system of additional education of children, which involves the organization by pupils of the space of their life based on choice, and contributing to the formation of a teenager's readiness for self-development. The pedagogical support of the self-development of adolescents acts as the target function of additional education.

5. The reflective-value approach to the pedagogical support of the self-development of adolescents in additional education is able to resolve the contradiction between the need of adolescents to solve existing problems (personal, social, etc.) on the path to achieving the goal and the lack of willingness to build a project of their own life.

\section{ACKNOWLEDGMENT}

The reported study was funded by RFBR, project number 20-013-00616.

\section{REFERENCES}

[1] M. Cai, Professional Self-Development Based on Informal Learning: A Case Study of Foreign Language Teachers in a University of China, Open Journal of Social Sciences, 7(12) (2019) 26.

[2] A. Carr, Positive, Psychology and You: A SelfDevelopment Guide, Routledge, 2019. DOI: https://doi.org/10.4324/9780429274855

[3] G. Edwards, A.F. Turner, Problematising'selfdevelopment in leadership learning, 2020, Available at: uwe-repository.worktribe.com.

[4] A. Khafizova, V. Zakirova, Effective-Practical and Creative (Heuristic) Pedagogical Technologies of Students' Self-Development, in: ARPHA Proceedings, No 1, 2019, pp. 1037-1042. DOI: 10.3897/ap.1.e0983

[5] I. Maksymchuk, O. Sahach, I. Demchenko, S. Furdui, B. Maksymchuk, O. Protas, E. Kyzko, Selfdevelopment in the context of forming the future teacher's pedagogical skills, Scientific Journal of National Pedagogical Dragomanov University. Series 15. Scientific and pedagogical problems of physical culture (physical culture and sports) 2(122) (2020) 8895. DOI: https://doi.org/10.31392/NPUnc.series15.2020.2(122). 18

[6] T. Ng, Experiences of chinese young people in devising their self-development plans in Hong Kong: a qualitative study, Asia Pacific Journal of Educators and Education 34 (2019) 167-185. DOI: https://doi.org/10.21315/apjee2019.34.9

[7] I. Yarmakeev, A. Kaplan, N. Valiakhmetova, R. Akhmadullina, A. Sharafieva, Intra-School Support for Professional Self-Development of Teachers, Int J Edu Sci 27(1-3) (2019) 39-44. DOI: $10.31901 / 24566322.2019 / 27.1-3$

[8] Y. Zhan, Z.H. Wan, College Students' Possible L2 Self Development in an EFL Context during the Transition Year, English Language Teaching 9(1) (2016) 41-50. DOI:10.5539/elt.v9n1p41

[9] L.S. Vygotsky, Psychology of human development, Publishing house Sense, Eksmo Publishing House, 2005.

[10] V.V. Davydov, An active approach in psychology: problems and prospects, APN USSR, 1990. 
[11] M. Cle, Psychology of adolescents: Psychosexual development, Pedagogy, 1991.

[12] A.N. Leontiev, Activity Consciousness. Personality, Meaning, IC Academy, 2005.

[13] J. Piaget, Selected psychological works, Education, 1969

[14] G.S. Sullivan, Interpersonal theory in psychiatry, KSP+, Juventa, 1999.

[15] V.I. Slobodchikov, Essays on the psychology of education, Publishing House of the Belarusian State Pedagogical Institute, 2003.

[16] D.I. Feldstein, Psychology of a developing personality, Institute of Pract. Psycho, NPO MODEK, 1996.

[17] S. Hall, The story of one pile of sand, Essays on the study of the child, Puchina, 1925.

[18] G.A. Zuckerman, Psychology of selfdevelopment: a task for adolescents and their teachers, Experiment, 1995.

[19] D. Elkind, Eric Erickson and the eight stages of human life, Raygorodsky D.Ya. Psychology of Personality, Samara, 1999.

[20] B.D. Elkonin, Development Psychology, Textbook. manual for universities, Academy, 2005.

[21] E. Erickson, Childhood and Society, Flint, 2006.

[22] V.A. Berezina, Additional education for Russian children, Dialogue of Cultures, 2007.

[23] A.K. Brudnov, The development strategy of state and municipal institutions of additional education, Education of schoolchildren 5 (1994) 2-4.

[24] V.P. Golovanov, Modern continuing education of children in the territory of a promising and safe childhood, Vestnik KGU named by Nekrasov, Pedagogy. Psychology. Social work. Juvenology. Sociokinetics 1-2 (2012) 138-144.

[25] V.A. Gorsky, Zhurkina A.Y, The pedagogical principles of the development of the system of additional education of children, Additional education 2 (1999) 4-6.

[26] E.E. Chepurnykh, Children's public organizations in the new century, Education of schoolchildren 3

(2004) 2-9.
[27] M.I. Rozhkov, The concept of existential pedagogy, Yaroslavl Pedagogical Bulletin 4 (2011) 4347.

[28] M.I. Rozhkov, T.N. Sapozhnikova, Reflexiveactivity approach to the education of social responsibility of youth: a monograph, Publishing House of YAGPU, 2010.

[29] E. Fromm, Man for himself, AST, 2008.

[30] D.C. McClelland, The Achievement Motive, Appleton-Century-Crofts, 1953.

[31] L.G. Peterson, Yu.V. Agapov, Motivation and self-determination in educational activities,

Agribusiness and missile defense, Institute of SocialDemocratic Party, 2011.

[32] P.M. Jacobson, Psychological problems of motivation of human behavior, Education, 1969.

[33] S.L. Rubinstein, Problems of general psychology, Pedagogy, 1976.

[34] N.A. Chueva, Age dynamics of life design, Bulletin of Tula State University. Humanitarian sciences 2 (2013) 284-294.

[35] O.S. Grebenyuk, T.B. Grebenyuk, The basics of personality pedagogy: a training manual, 2000.

[36] V. Frankl, Man in search of meaning, Progress, 1990.

[37] K.A. Abulkhanova-Slavskaya, Life strategy, Thought, 1991.

[38] J.-P. Sartre, Existentialism is Humanism, Twilight of the Gods, 1990.

[39] D.A. Leontiev, New guidelines for understanding personality in psychology: from necessary to possible, Psychology Issues 1 (2011) 13-14.

[40] V.S. Mukhina, Personality: Myths and Reality (Alternative view. Systematic approach. Innovative aspects), Prometheus, 2010.

[41] V.A. Petrovsky, Personality in psychology: the paradigm of subjectivity, Phoenix, 1996.

[42] T.N. Sakharova, Age dynamics of the meaning of life orientations of a person, Bulletin of the Voronezh State Technical University 8(10-2) (2012) 156-160. 
[43] Z.V. Golysheva, The dynamics of life-meaning orientations (longitudinal research), in: Psychological problems of the meaning of life, Materials of the 14th symposium, 2009.

[44] I.V. Ivanova, The pedagogical support of the formation of a teenager's perception of the situation of overcoming difficulties as opportunities for selfdevelopment, Education of schoolchildren 8 (2019) 5162 .

[45] H. Sek, Orientation in social situations a clinical theoretical study, Poznan, 1980. 